CARlos Frederico Barbosa Bentivegna

\title{
O DANO MORAL PELO ABUSO DA LIBERDADE DE EXPRESSÃO E DE MANIFESTAÇÃO DO PENSAMENTO
}

DisSERTAÇÃO DE MESTRADO

UNIVERSIDADE DE SÃO PAULO

FACULDADE DE DIREITO

SÃo PAULO

OUTUBRO DE 2018 


\title{
O DANO MORAL PELO ABUSO DA LIBERDADE DE EXPRESSÃO E DE MANIFESTAÇÃO DO PENSAMENTO
}

\author{
Dissertação apresentada à Banca \\ Examinadora do Programa de Pós-Graduação \\ em Direito, da Faculdade de Direito da \\ Universidade de São Paulo, como exigência \\ parcial para obtenção do título de Mestre em \\ Direito na área de concentração de Direito \\ Civil, sob a orientação do Professor Titular \\ Doutor Rui Geraldo Camargo Viana.
}

UNIVERSIDADE DE SÃO PAULO

FACULDADE DE DIREITO

SÃO PAULO

OUTUBRO DE 2018 
Banca Examinadora: 


\section{RESUMO}

O presente trabalho de ocupa da natural tensão verificada quando postos frente a frente o direito à livre expressão do pensamento de alguém e os direitos da personalidade, mais especificamente a imagem, a honra e a privacidade, de quem seja objeto daquela ideia manifestada.

Trata-se de reconhecer, em primeiro lugar, a importância e a essencialidade dos direitos da personalidade, como elementos indispensáveis ao desenvolvimento pleno de alguém enquanto pessoa humana; bem como de admitir a liberdade de expressão e de manifestação de pensamento como parte desses atributos pessoais indispensáveis à constituição de uma pessoa íntegra, plena e apta a viver em sociedade. Para tanto, o trabalho foi às origens históricas da proteção de tais direitos, às Cartas Políticas e Declarações Universais antes de analisar o estado da arte na proteção dos postulados em potencial situação de conflito.

Em seguida, tratou o autor de descrever a necessária ponderação entre princípios de mesma hierarquia constitucional para que o caso concreto aponte qual deles deve prevalecer: (i) a liberdade de expressão - obrigando o alvo da notícia, manifestação artística, literária ou comentário a suportar a opinião que lhe seja desfavorável - ou (ii) os direitos de personalidade deste último - sua honra, sua intimidade, vida privada ou imagem, por exemplo - que, uma vez vulnerados, dão azo à mitigação dos danos morais.

Quanto aos danos morais, estudou-se o conceito, as teorias que aceitavam e que negavam a sua mitigação em dinheiro a partir de fins do Século XIX até a promulgação da Constituição Federal de 1988 que previu a "indenização" dos danos independentes de morais ou materiais. Por fim, cuidou-se do grave problema da quantificação da condenação dos danos morais e o cabimento de punitive damages e danos sociais no direito brasileiro.

PALAVRAS CHAVE: Danos morais - Conflitos entre Princípios Constitucionais - Direitos da Personalidade - Abuso da Liberdade de Expressão - Quantificação dos Danos Morais Dano Social - Tutela Preventiva de Danos Morais - Censura Prévia 


\section{ABSTRACT}

The present work deals with the natural tension that occurs when are placed face to face the right to free expression of one's thoughts and the rights relating to the personality, more specifically the image, honor and privacy, of whoever is object of that manifested idea.

It is a question of recognizing first and foremost the importance and essentiality of the rights relating to the personality as essential elements for the full development of someone as a human being; as well as to admit freedom of expression and expression of thought as part of these personal attributes indispensable to the constitution of a person who is complete, full and able to live in society. For this, the work went to the historical origins of the protection of such rights, to the Bill of Rights and Universal Declarations before analyzing the state of the art in the protection of the postulates in potential situation of conflict.

The author then treated to describe the necessary weighting between principles of the same constitutional hierarchy in order to define which one should prevail in a concrete case: (i) freedom of expression - compelling the target of the news, the artistic or literary expression or the commentary to bear the opinion that is unfavorable to him or her, or (ii) the rights relating to the personality of the latter - his/her honor, intimacy, private life or image, for example - that, once violated, give rise to the mitigation of moral damages.

Regarding moral damages, the concept was studied as well as the theories that accepted and denied their mitigation in currency from the late nineteenth century until the promulgation of the 1988 Federal Constitution that provided for "compensation" for damages independently of their nature: moral or materials. Finally, the serious problem of the quantification of the condemnation of moral damages and the fitting of punitive damages and social damages in Brazilian law was taken care of.

KEY WORDS: Moral Damage - Conflicts between Constitutional Principles - Rights relating to the Personality - Abuse of Freedom of Expression - Quantification of Moral Damages Social Damage - Preventive Protection of Moral Damages - Prior Censorship 


\section{SOMMARIO}

Questo lavoro si ocupa della tensione naturale che accade quando vengono afrontati il dirtitto alla libertà di espressione del pensiero di qualcuno ed i diritti della personalità, in particolare l'immagine, l'onore e la riservatezza, di chiunque sia l'oggetto dell'idea manifestata.

Si è dedicato a riconoscere, prima di tutto, l'importanza e l'essenzialità dei diritti della personalità, come elementi indispensabili per lo sviluppo pieno di chiunque come persona umana; oltre che per ammettere la libertà di espressione come parte di questi attributi personali indispensabili alla formazione di una persona intera, piena e adatta a vivere nella società. Per tanto, questo studio è tornato alle origine storiche della protezione di tali diritti, alle Carte Politiche e Dichiarazioni Universali prima di analizzare la protezione oggi data ai postulati in stato pontenziale di conflito.

In seguito, l'autore ha descrito la ponderazione necessaria tra i principi costituzionali della stessa gerarchia, in modo che il caso concreto indichi quale di loro dovrebbe essere maggiormente valutato: (i) la libertà di espressione - costringendo la persona bersaglio della notizia, manifestazione artistica, letteraria o commento a sopportare l'opinione che gli sia sfavorevole - o (ii) i diritti della personalità di quest'ultimo - il suo onore, riservatezza o immagine, ad esempio - che, una volta violati, danno origine alla mitigazione dei danni morali.

Sui danni morali, si sono studiati i concetti, le teorie che accettavano e che negavano la loro mitigazione in pecunia dalla fine del XIX secolo fino alla promulgazione della Costituizione del 1988 che prevedeva il risarcimento dei danni, independentemente dal fatto morale o materiale. Alla fine, si ha preso cura del serio problema della quantificazione della condanna per dani morali e della possibilità di applicare i danni punitivi e i danni sociali nel diritto civile brasiliano.

PAROLE CHIAVE: Danni Morali - Conflitti tra Principi Costituzionali - Diritti della Personalità - Abuso di Libertà di Espressione - Quantificazione dei Danni Morali - Danni Sociali - Tutela Preventiva dei Danni Morali - Censura Precedente 
Agradeço imenso a meus pais, Antonio Sergio Bentivegna e Sylvia Maria Lopes Barbosa Bentivegna, pelo apoio incondicional e pela oportunidade de sempre conviver com a cultura. Da mesma forma agradeço à minha mulher Pepita e a meus filhos Francisco e Frederico, aos últimos por me inspirarem a querer ser a melhor versão de mim mesmo e à primeira não apenas pelas "manjadas" horas roubadas ao convívio familiar, mas por ajuda ativa e incansável que ela sabe bem qual foi. Ainda em meu círculo familiar, agradeço a meu tio Mágino Alves Barbosa Filho pelo apoio e incentivo por ocasião de meu ingresso no Programa de Pós-Graduação, com palavras gentis de suma relevância e jamais esquecidas.

No ambiente acadêmico, meus primeiros agradecimentos devem ser dirigidos, sem sombra de dúvida, ao Professor Titular Rui Geraldo Camargo Viana, de quem tive o privilégio de ser orientando, e que nem parece ser uns cinco ou seis anos mais velho que nós, tamanho é seu desassombro em enfrentar questões as mais modernas e novidadeiras dentro da ciência do direito, emprestando seu descortino e sua erudição às mais criativas teses e saídas jurídicas, onde a maioria só vê obstáculos. Também no âmbito das Arcadas, devo expressar minha profunda gratidão ao Professor Titular Carlos Alberto Dabus Maluf, amigo há cinco décadas dos Bentivegna, dado que colega de meu pai da gloriosa Turma de 1970 do Largo de São Francisco, fonte inesgotável de indicações preciosas para minha pesquisa, com sua boa vontade e com o conhecimento de direito civil que são de todos conhecidos. Entre os professores da Casa, a Professora Titular Silmara Juny de Abreu Chinellato e os Professores Associados Otavio Luiz Rodrigues Junior e Antonio Carlos Morato também foram decisivos, na generosa interlocução que comigo estabeleceram, posto que houvesse um abismo entre as inteligências em interação. Aos ilustres Professores Doutores Adriana Caldas do Rêgo Freitas Dabus Maluf e Jorge Shiguemitsu Fujita, que participaram de minha banca de qualificação, direcionando decisivamente os rumos do presente trabalho, devo muito do que tenha eventualmente conseguido produzir de aproveitável, isentando-os dos erros que serão todos de minha exclusiva responsabilidade.

Aos também professores e amigos Doutor Alfredo Domingues Barbosa Migliore, que leu o manuscrito com generosa atenção e fez sugestões valiosíssimas, e Doutor Gilberto Haddad Jabur, que, profundo conhecedor do tema, foi um interlocutor de fundamental importância para a consecução dessa empreitada; manifesto aqui minha profunda gratidão. Agradeço também aos meus colegas de Pós-Graduação, que comigo dividiram as agruras dos prazos, das dúvidas, do medo da crítica, do medo de uma encarnação não ser o suficiente para ler todo o necessário. E aqui cito, especialmente, Fernando Speck de Souza, Viviane Daniel Speck de Souza, Atalá Correia, Paula Luciana Menezes, Anna Figueiredo, Ricardo Maffeis e Patrícia Cândido A. Ferreira.

Entre os amigos, frequentadores de minha casa, tenho de destacar aqueles que trocaram valiosas ideias comigo sobre este trabalho, começando por André de Godoy Fernandes, cuja tese de doutoramento - vencedora do prêmio de melhor Tese da USP de 2009 - é aqui citada, que leu o esboço da dissertação e fez apontamentos preciosos, Joel Luiz de Thomaz Bastos, Cristiano Ávila Maronna e sua mulher Priscila Akemi Beltrame, todos leitores de esboços de capítulos e incomodados, com frequência muito maior do que a justa, para que me brindassem com suas preciosas opiniões. Muito obrigado a todos. Aos meus colegas do escritório Bentivegna e Ribeiro Sociedade de Advogados, Daniani Ribeiro Pinto, Juliana Raffo Montero, Paula Malandrin, Débora Fernandes e Bruna Trajano, com quem discuti os temas aqui tratados e que ocuparam minha mente durante as 24 horas do dia. O risco desses agradecimentos nominais é o velho adágio: "A gente nunca se esquece de quem se esquece da gente!" Espero não ter me esquecido de ninguém que tenha me ajudado nessa empreitada, muito obrigado a todos! 
Dedicatória:

A

Francisco Rodrigues Bentivegna, meu amado filho, cientista. De quem, num cochilo do tempo e ordem natural, EU herdei a curiosidade sem fim. 
Nemo damnum facit, nisi qui id fecit quod facere jus non habet

(Ninguém perpetra dano, a não ser que tenha feito o que não tinha o direito de fazer) 


\section{SUMÁRIO}

INTRODUÇÃO ............................................................................................17

$\S 1$. A liberdade de expressão e a mitigação do dano moral....................................................17

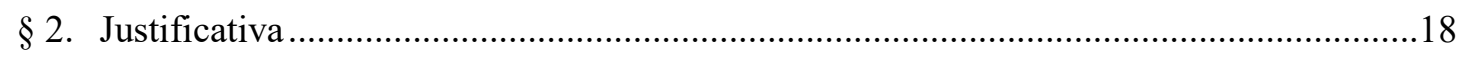

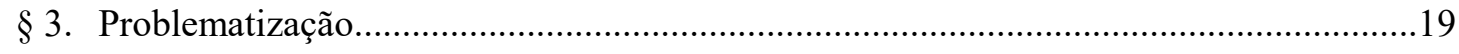

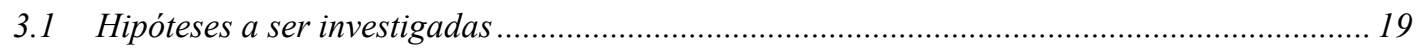

\section{PARTE I - DIREITOS DA PERSONALIDADE RELACIONADOS À INTEGRIDADE MORAL E COLISÃO DE PRINCÍPIOS CONSTITUCIONAIS........................................................................................... 25}

Capítulo 1 - Conceitos de Personalidade e de Direitos da Personalidade ........ 27

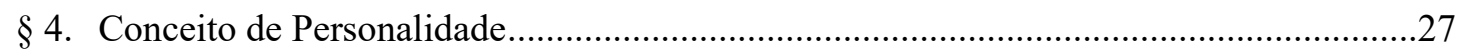

§ 5. Conceito de Direitos da Personalidade ………..................................................................

§ 6. Direitos da Personalidade e Pessoas Jurídicas ......................................................................

§ 7. Existência de um Direito Geral da Personalidade .............................................................38

CApítulo 2 - ClassificaÇÕes e CARACTERÍSTICAS dos Direitos DA Personalidade43

§ 8. Classificações dos Direitos da Personalidade ......................................................................43

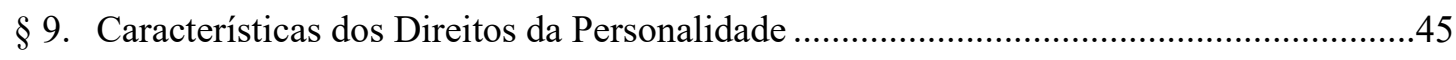

Capítulo 3 - Paralelismo entre Direitos da Personalidade, Direitos

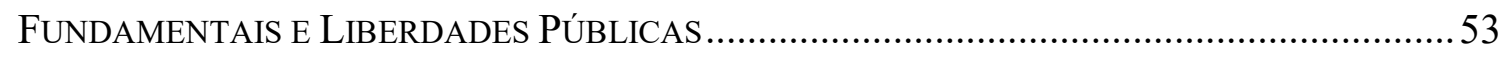

Capítulo 4 - Liberdade de ExPressão e de ManifestaÇão do Pensamento............ 59

$\S 10$. Normas matrizes internacionais sobre o tema ao longo da história ...................................65

$\S 11$. O uso e o abuso da liberdade de expressão e de manifestação do pensamento .................68

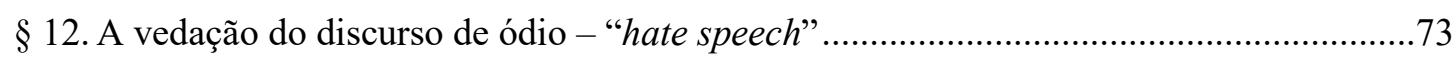

12.1 Exame de Caso concreto - Caso Bolsonaro: incitação ao crime de estupro ........................... 77

$\S 13$. As limitações da Liberdade de Expressão na jurisprudência estrangeira ..........................79

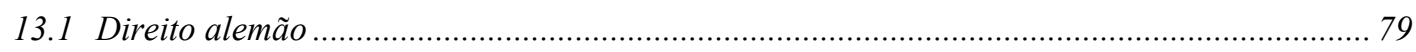

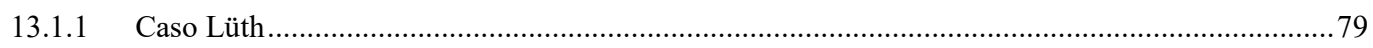

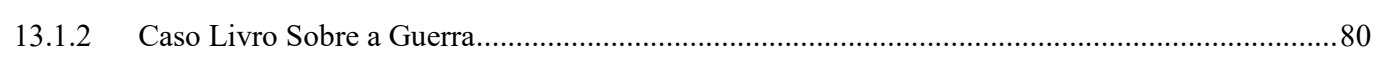

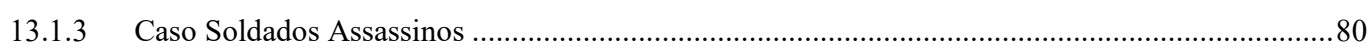




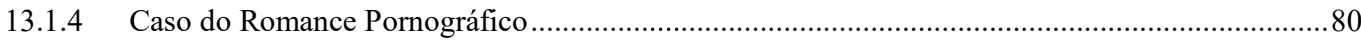

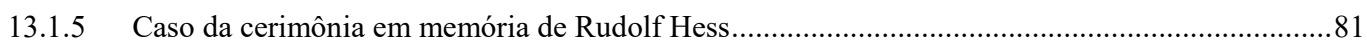

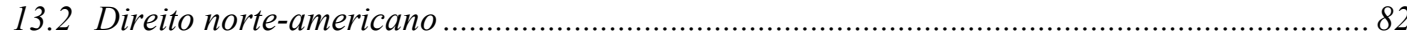

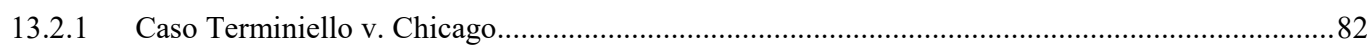

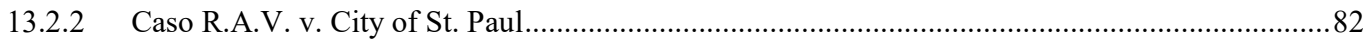

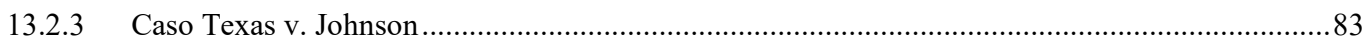

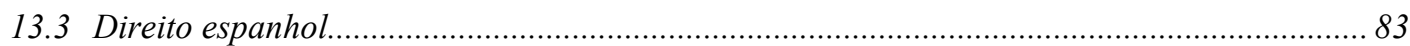

13.3.1 Caso da Publicação Cômica contra o Povo Judeu ...........................................................................8

CAPÍTUlo 5 - Proteção À HonRA, À IMAgEM, À INTIMIDAde E À PriVACIDADE..............85

$\S 14$. Conceito de Honra das acepções de honorabilidade Objetiva e Subjetiva ........................86

14.1 Caso concreto: Michel Temer X Joesley Batista.............................................................. 94

$\S 15$. Conceito de Imagem - Crítica à elasticidade do conceito de imagem-atributo...............102

15.1 Teorias acerca da existência de um direito autônomo à própria imagem............................. 106

15.2 O direito à própria imagem na Constituição Federal de 1988 e no Código Civil de 2002 ... 108

15.3 Conclusões pontuais e alguns casos concretos 109

$\S$ 16. Privacidade - Intimidade e Vida Privada tal como protegidas pela Constituição Federal 115

16.1 Direito à vida privada e à intimidade de pessoas jurídicas .................................................... 126

16.2 Exame de alguns casos concretos na jurisprudência brasileira e estrangeira ...................... 128

$\S$ 17. Alguns casos de proteção aos direitos à liberdade de expressão e à honra, à imagem, à vida privada e à intimidade julgados nos Tribunais de Justiça dos Estados e do DF

CAPÍTULO 6 - COLISÃO DOS PRINCÍPIOS CONSTITUCIONAIS: LIBERDADE DE EXPRESSÃO VS. PROTEÇÃO À HONRA, À IMAGEM, À INTIMIDADE E À PRIVACIDADE

§ 18. Circunscrição do tema ao Sistema de Direito Civil - Inocorrência in casu de

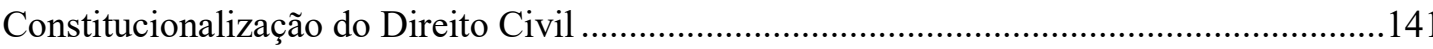

$\S 19$. Conflito de princípios constitucionais de mesma estatura

CAPÍTULO 7 - A LIBERDADE DE EXPRESSÃO É DIREITO FUNDAMENTAL PREFERENCIAL PRIMA FACIE?

$\S 20$. Exame de caso concreto: O Caso Siegfried Ellwanger (HC 82.424-2 RS, STF) 164

CAPÍTUlO 8 - ELEMENTOS A SER LEVADOS EM CONSIDERAÇÃO NA PONDERAÇÃO ENTRE OS PRINCÍPIOS EM COLISÃO AQUI EXAMINADOS

$\S$ 21. Redução da esfera de proteção dos direitos da personalidade de pessoas ditas "pessoas públicas" 169 
22.1 Caso Melvil v. Reid - EUA.....

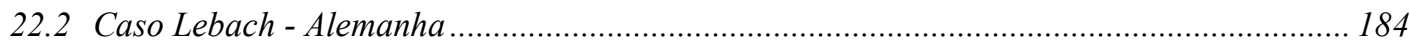

22.3 Caso Ainda Curi - Brasil ............................................................................................ 185

22.4 Caso Chacina da Candelária - Brasil........................................................................ 188

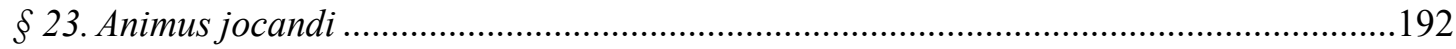

$\S 24$. Redução da esfera de proteção dos direitos da personalidade do criminoso ou do acusado do cometimento de crime

\section{PARTE II - DANO MORAL: EVOLUÇÃO HISTÓRICA DO INSTITUTO, CONCEITO E FENÔMENO DO DANO MORAL EM FACE DAS PESSOAS JURÍDICAS ........................................................... 207}

CAPÍTULO 1 - EVOLUÇÃO HISTÓRICA DO INSTITUTO DO DANO MORAL NA DOUTRINA ..... 209

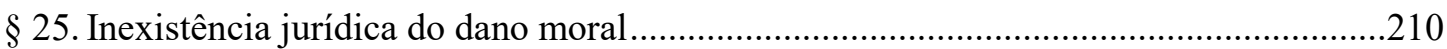

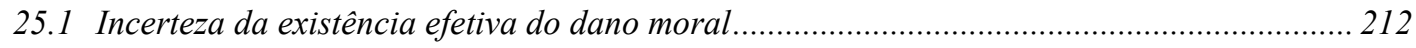

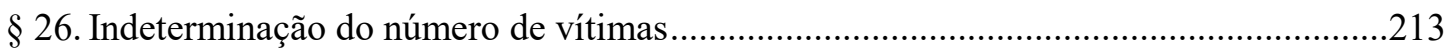

$\S 27$. Impossibilidade de rigorosa avaliação pecuniária dos danos morais. Imoralidade do

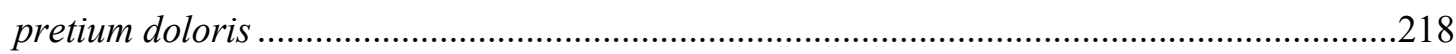

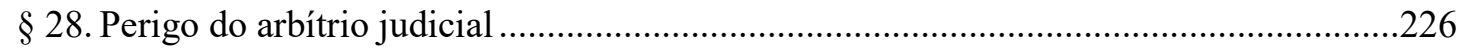

§ 29. A chamada Teoria Eclética ou Teoria Mista ....................................................................229

$\S 30$. Silêncio de alguns doutrinadores quanto à polêmica da reparabilidade de danos morais 231

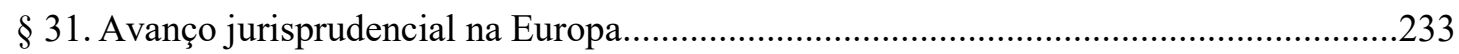

CAPÍTUlO 2 - EVOLUÇÃo DOS DANOS MORAIS NO ORDENAMENTO JURÍDICO E

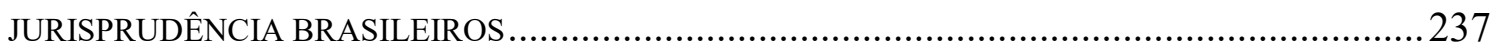

§ 32. O dano moral no direito posto brasileiro até a Constituição Federal de 1988 ................237

§ 33. A Constituição Federal de 1988 .....................................................................................247

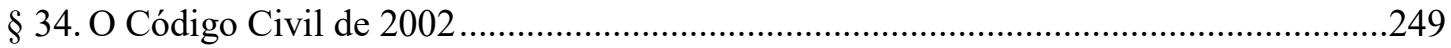

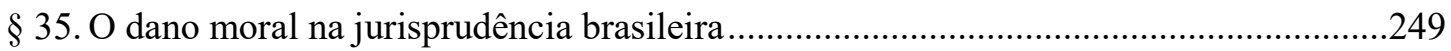

CAPÍTULO 3 - DANO MORAL: CONCEITO E PRINCIPAIS CORRENTES DOUTRINÁRIAS ........263

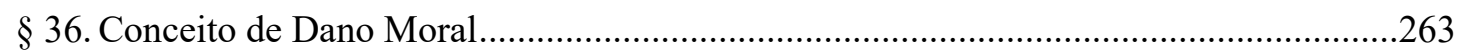




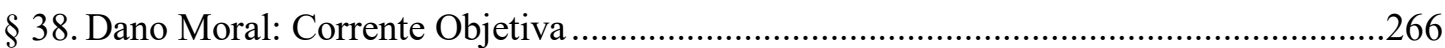

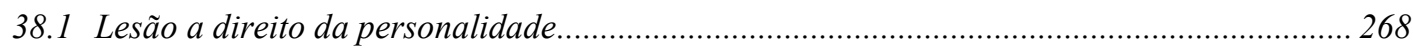

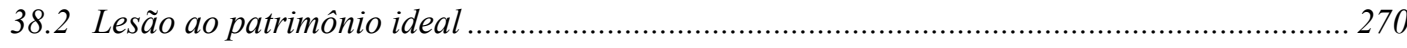

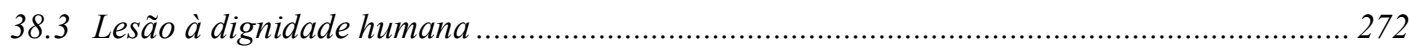

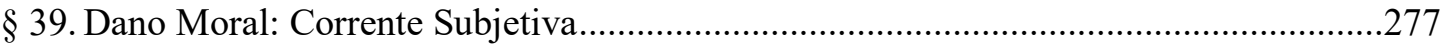

CAPÍTULO 4 - DANO MORAL COMO “DANO-EVENTO” E COMO “DANO-PREJUÍZO”

CAPÍTULO 5 - TENTATIVA DE CONSTRUÇÃO DE UMA TEORIA ECLÉTICA E FORMULAÇÃO DO

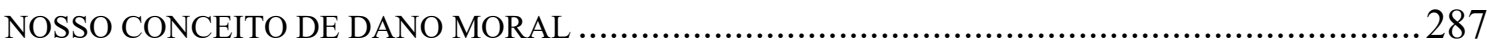

CAPÍTULO 6 - FENÔMENO DO DANO MORAL EM FACE DAS PESSOAS JURÍDICAS ...............291

$\S 40$. Conceito dominante na Jurisprudência Brasileira .........................................................291

$\S 41$. Honorabilidade objetiva e outros aspectos da personalidade das pessoas jurídicas tutelados pelo direito

§ 42. Jurisprudência brasileira anterior à edição da Súmula nº 227 do STJ

$\S 43$. Dano moral e pessoa jurídica - teorias "negativistas" e "afirmativas" de seu cabimento no

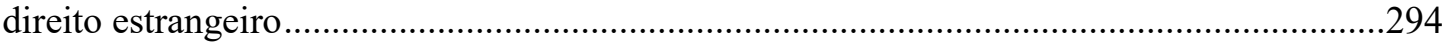

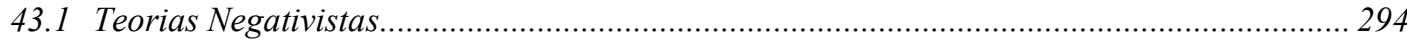

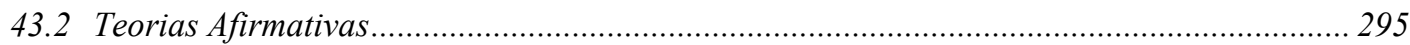

43.3 O entendimento doutrinário no Brasil quanto ao cabimento do dano moral às pessoas jurídicas 296

$\S 44$. Conflito entre direitos fundamentais de: liberdade de expressão e de honra da pessoa jurídica

$\S 45$. Conclusão quanto ao cabimento ou não - nossa posição ...................................................299

$\S$ 46. Novo Paradigma do Dano Moral - conceituação mais moderna do Dano Moral. 300

$\S 47$. Crítica à conceituação proposta até o momento para o instituto do dano moral e tentativa de construção de um conceito abrangente e tecnicamente preciso

\section{PARTE III - TUTELA PREVENTIVA E MITIGAÇÃO DOS DANOS MORAIS POR OFENSA À HONRA, À IMAGEM, À INTIMIDADE E À


$\S$ 48. Contexto histórico do início da vedação à censura e da garantia à liberdade de expressão 307

$\S 49$. Tutela preventiva da personalidade vs censura nos dias de hoje. .310

49.1 Exame de caso concreto de Tutela Preventiva: Caso "Lampião, o mata sete"......

CAPÍTULO 2 - RESPONSABILIDADE CIVIL - TUTELA “REPARATÓRIA” DOS DiREITOS DA

PERSONALIDADE

$\S 50$. Responsabilidade Civil

$\S 51$. Evolução histórica da responsabilidade civil a partir do Direito Romano. .330

$\S 52$. A Responsabilidade Civil - do Código Civil Francês à Revolução Industrial 334

$\S 53$. Responsabilidade civil no Brasil nos dias atuais .336

§ 54. Classificação dos danos ..... .339

CAPÍtulo 3 - MeCANismo de Mitigação dos Danos Morais.

CAPÍTUlO 4 - A MitigaÇÃo dos DANOS MORAIS NA CONSTITUIÇÃO DE 1988 E NO CÓDiGO

CIVIL DE 2002

$\S 55$. A mitigação dos danos morais na $\mathrm{CF} / 1988$ e o direito de resposta 347

$\S 56$. O direito de resposta coletivo .350

§ 57. A mitigação dos danos morais no $\mathrm{CC} / 2002$

CAPÍTULO 5 - O PROBLEMA DO TABELAMENTO E DO ARBITRAMENTO JUDICIAL DO QUANTUM MITIGATÓRIO DOS DANOS MORAIS

$\S 58$. Inconstitucionalidade da tarifação legal do quantum mitigatório 357

$\S 59$. Tentativas frustradas de Projetos de Lei a reeditar a "tarifação" do quantum mitigatório dos danos morais . .362

59.1 Projeto de Lei $n^{\circ} 7.124$ de 2002 do Senado Federal.............................................................. 362

59.2 Projeto de Lei do Senado $n^{\circ} 334$ de 2008 364

§ 60. Recente caso de "tarifação" implementada pela Lei 13.467/2017 (Reforma Trabalhista) 366

CAPÍtUlo 6 - PossibILIDADE DE APLICAÇÃO DE PUNITIVE DAMAGES NO BRASIL 371

$\S 61$. A aplicação dos punitive damages ao longo da história 376

$\S 62$. Os punitive damages na jurisprudência de alguns países da Europa Continental 379

62.1 Caso Security Fowards Inc. v. Trans Containers Services A. G. 382 
62.2 Caso "John Doe"

62.3 Os punitive damages no direito italiano ................................................................. 386

$\S 63$. Os punitive damages no direito norte-americano hoje ........................................389

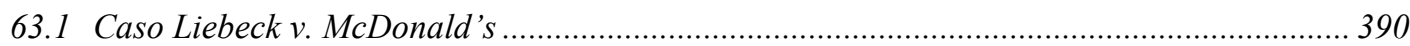

63.2 Caso BMW of North America, Inc. v. Gore ........................................................................... 393

63.3 Caso TXO Production Corp. v. Alliance Resources Corp ............................................... 396

$\S$ 64. Teoria do dano social de Antonio Junqueira de Azevedo - nossa posição...................398

CAPÍtulo 7 - O MÉTOdo BIFÁSICO APLICADO PELO STJ .......................................... 403

$\S$ 65. O Acórdão paradigmático inaugural da Colenda $3^{\mathrm{a}}$ Turma do STJ - Min. Paulo de Tarso Sanseverino .403

$\S$ 66. Aplicação pela Colenda $4^{\mathrm{a}}$ Turma do STJ em casos a envolver nosso objeto de estudo406 $\S$ 67. Análise do cabimento do método bifásico em face do Ordenamento Brasileiro e sua utilidade

CAPÍtulo 8 - O PROBlEMA DA FiXAÇÃO DO QUANTUM MitiGATÓRIO: ARBÍTRIO JUDICIAL E TENTATIVA DE BALIZAMENTO LEGAL

$\S$ 68. Critérios a ser levados em conta para a fixação do quantum mitigatório segundo diversos autores

$\S 69$. Nossa posição quanto aos critérios a presidir a fixação do quantum mitigatório dos danos morais

CONCLUSÃO

REFERÊNCIAS BIBLIOGRÁFICAS

LIVROS

OBRAS GERAIS

OBRAS MONOGRÁFICAS

CAPÍTULOS DE LIVROS 
TESES E DISSERTAÇÕES

459

TEXTOS EM MEIO ELETRÔNICO

460 


\title{
INTRODUÇÃO
}

\section{§ 1. A liberdade de expressão e a mitigação do dano moral}

O objetivo do presente trabalho é estudar a necessária mitigação do dano moral de quem atingido em sua esfera de direitos personalíssimos pelo abuso alheio no exercício da liberdade de manifestação de suas opiniões. O tema dos danos morais e sua reparação esteve muito em voga no início dos anos 1990, tendo sido debatido ad nauseam no ambiente acadêmico para depois sofrer certo abandono, dando a falsa impressão de tratar-se, hodiernamente, de tema "velho" ou de uma discussão anacrônica ou mesmo redundante.

Nada mais distante da realidade, no entanto.

Já em 2009, Antonio Junqueira de Azevedo advertia ${ }^{1}$ :

\begin{abstract}
"O grande tema, em matéria de responsabilidade civil, na década de noventa, foi o dos danos morais, apesar, porém, do tempo decorrido, da intensa produção doutrinária e da vasta jurisprudência, não se chegou a nenhum critério que pudesse pacificar o debate sobre sua quantificação. Se essa questão, hoje, parece menos vibrante, isso se deve antes ao cansaço dos contendores que ao fato de terem encontrado uma solução. Certamente uma das grandes dificuldades para essa não-conclusão dos juristas brasileiros foi a falta de acordo sobre os exatos fundamentos da responsabilidade pelos danos morais, ou seja, sobre se a indenização constituía somente uma espécie de compensação por sofrimentos psíquicos e lesões a direitos de personalidade, inclusive de pessoas jurídicas, ou se devia também incluir um plus, os chamados "punitive damages". Ademais, nesses "punitive damages", grande parte da doutrina brasileira, à semelhança da norteamericana, ora tinha em vista uma punição do agente ora uma dissuasão ou desestímulo, à prática de atividades nocivas”.
\end{abstract}

Diversas são as questões deixadas em aberto pelos estudiosos, envolvendo em lacunas exegéticas o instituto do dano moral, mas, pior que isso, diversas são as contradições diametrais a que se entrega a jurisprudência sem que os julgadores se disponham a enfrentar apropriadamente o tema e as dificuldades que ele proporciona. Exemplificam-se facilmente tais contradições com (i) o fato de a imensa maioria dos julgados referirem-se aos danos morais como sentimento de dor, vexação, tristeza e, sem qualquer ressalva, em seguida atribuírem-nos às pessoas jurídicas, ou (ii) o fato de se reputar antijurídica a hipótese de pena

\footnotetext{
${ }^{1}$ AZEVEDO, Antonio Junqueira de. Novos estudos e pareceres de direito privado. São Paulo: Saraiva, $2009, \mathrm{p}$. 377
} 
privada, afirmando incabível no Brasil a aplicação dos punitive damages - possível apenas na tradição do common law -, principalmente em virtude do disposto no art. 944 do CC/2002, enquanto, ao fundamentar a decisão, em seguida, afirmam que o valor arbitrado é adequado por cumprir bem sua função de reparar o dano sofrido e dissuadir o ofensor de novos ataques, ou ainda (iii) o fato de o Poder Judiciário banir do sistema a antiga Lei de Imprensa (Lei Federal n $n^{\circ}$ 5.250/67) por inconstitucional, vez que apresentava "tabelamento" ou "tarifação" do quantum debeatur nas hipóteses de reparação dos danos morais, enquanto este mesmo Poder Judiciário, logo em seguida, estabelece um "tabelamento", disfarçado sob a pomposa designação de "sistema bifásico" de quantificação da indenização dos danos morais. Será mesmo o sistema bifásico uma forma de "tarifação judicial”? Outros exemplos haveria e muitas hipóteses de problematização ocorrerão ao longo deste trabalho de forma a comprovar a atualidade e necessidade da discussão que ora se propõe.

\section{§ 2. Justificativa}

A escolha do tema se justifica em face da crescente litigiosidade entre os exercentes de sua liberdade de expressão e aqueles atingidos em sua honorabilidade, em sua intimidade ou pela exposição de sua imagem, de forma a experimentar danos morais advindos do abuso desse direito à livre manifestação do pensamento.

Com a decretação da não recepção in totum da Lei de Imprensa (Lei n ${ }^{\circ} 5.250$ de 1967) pela Constituição Federal de 1988, feita pelo Supremo Tribunal Federal, uma das ferramentas para apaziguar grande parte dos conflitos deixou de estar disponível, tendo com ela desaparecido o rito já consagrado do direito de resposta e outras técnicas até então eficazes - até certa medida - para atender aos conflitos surgidos nessa seara das relações sociais.

Hoje, com a expansão significativa dos meios de comunicação social - a partir das redes sociais, dos blogs, das mídias alternativas - as pessoas encontram muito mais facilidade para publicação de suas opiniões e impressões sobre os mais variados assuntos e pessoas, o que oportuniza, por óbvio, a veiculação de juízos desfavoráveis sobre outras pessoas ou a exposição de aspectos de suas vidas privadas ou intimidades. Essa aproximação perigosa do círculo mais íntimo do outro, com (i) a crítica que pode exceder aspectos públicos e avançar para questões que difamem ou firam o decoro do alvo da crítica, ou com (ii) a exposição que pode mostrar mais do que a pessoa objeto daquele descortino gostaria de ver publicado sobre 
sua esfera privada; tem o potencial de causar dano moral, através de ataque a bens jurídicos protegidos da vítima (dano-evento, ou a lesão ao bem da vida), gerando a vulneração de direito da personalidade desta que, geralmente se manifesta num menoscabo anímico, ou seja, uma redução no arcabouço das afeições do lesado, fazendo-o experimentar tristeza e dor (dano-prejuízo, ou a consequência dessa lesão) - tristeza, dor e vexação que em alguns casos podem não se apresentar (são sintomas possíveis e não conditio sine qua non do dano moral): como no das pessoas jurídicas ou no daquelas privadas de consciência) que deverão ser mitigadas com uma espécie de "fator compensatório gerador de alegria".

\section{§3. Problematização}

Toda essa operação envolve grande número de desafios técnico-jurídicos, como (i) a superação da antinomia real entre princípios constitucionais; (ii) o estabelecimento do real alcance da chamada "supremacia" do interesse público sobre o particular em casos como os de confronto entre a informação do público e a revelação da intimidade de alguém; (iii) a perfeita caracterização do que é dano moral, diferenciando-o dos meros dissabor, contrariedade ou frustração; (iv) a adequação terminológica (que parece ser uma questão de menor importância, apenas semântica, mas não é) da "indenização" do dano moral - como trata a Constituição Federal - para algo como mitigação (visto que "reparação" é sinônimo de "indenização" e "compensação" já tem outra acepção técnica no Direito Civil), já que é impossível tornar indene a vítima do dano moral, sendo a maioria dos danos morais indeléveis; (v) a difícil questão da quantificação desta mitigação do dano moral; (vi) os novos paradigmas das relações jurídicas de responsabilidade civil, com o reconhecimento de novas modalidades de danos, como dano patrimonial, moral, estético, biológico, psíquico e a possibilidade de cumulação de sua mitigação ante o mesmo evento danoso; (vii) a possibilidade ou não de tutelas inibitórias ou preventivas a par das condenações pecuniárias posteriores ao dano e como coadunar estas eventuais medidas com a vedação constitucional à censura; etc.

\subsection{Hipóteses a ser investigadas}

Acredito que, a partir do desenvolvimento do presente trabalho, ao final possamos contribuir para a investigação mais acurada - ou mesmo para o deslinde - das hipóteses seguintes: 
(i) Inexistência de maior valoração apriorística da liberdade de expressão, em face de suposta "supremacia do interesse público", em confronto com a inviolabilidade da honra, da imagem, da intimidade e da vida privada.

(ii) Responsabilidade civil como alternativa mais efetiva para o enfrentamento das violações aos direitos da personalidade pelo abuso da liberdade de expressão, em face da proximidade entre tutelas inibitórias e censura prévia (não em todos os casos) e da ineficácia isolada do direito de resposta.

(iii) Dano moral não é passível de indenização, pois dele não se pode ficar “indene”. Reparação é sinônimo de indenização e compensação já tem acepção técnico-jurídica própria e diversa. Talvez a melhor alternativa semântica seja a mitigação do dano moral por violação da honra, imagem, intimidade ou vida privada.

(iv) Conceito de imagem-atributo se sobrepõe ao conceito de honra objetiva e imagem deveria limitar-se à identificação biotípica da pessoa, deixando reputação e atributos de natureza social para o conceito de honra trazido pelo mesmo dispositivo constitucional.

(v) É possível o deferimento de tutela inibitória em face de possível e iminente violação da honra, imagem, intimidade ou vida privada através de abuso no exercício da liberdade de expressão? Quid juris em face da vedação da censura? Por outro lado, como compatibilizar a eventual proibição da tutela inibitória com a inafastabilidade da tutela jurisdicional a todo ato ou ameaça" do inciso xxxv do art. $5^{\circ}$ ?

(vi) Mecanismo de compensação do "patrimônio" anímico lesionado pela causação de um sentimento negativo de dor ou sofrimento. Necessidade de gerar alegria, suprida apenas com prestação in pecunia capaz de proporcionar uma satisfação espiritual. Afastamento da crítica quanto ao pretium doloris.

(vii) Dano Moral é o efeito não patrimonial da lesão ao interesse juridicamente protegido e não uma lesão sobre bem jurídico extrapatrimonial. Além da lição de Aguiar Dias sobre essa distorção, vale buscar na doutrina italiana, em 
Alfredo Minozzi² quando diz com invulgar precisão que: "a diferenciação do dano entre patrimonial e não patrimonial não se refere ao dano em sua origem, mas ao dano em seus efeitos. Quando falamos de danos não patrimoniais, pretendemos falar daqueles que não lesam o patrimônio da pessoa. O conteúdo desses danos não é o dinheiro, nem um bem comercialmente redutível a dinheiro, mas sim a dor, o susto, a emoção, a vergonha, o tormento físico ou moral, em geral uma sensação dolorosa experimentada pela pessoa, atribuindo-se à palavra dor o mais amplo significado".

(viii) A existência, além do "patrimônio" na acepção clássica do termo, de um "patrimônio moral" ou "patrimônio afetivo", que seria o arcabouço das afeições e dos sentimentos da pessoa humana; podendo sofrer diminuição (menoscabo) ou recomposição (através da mitigação do dano moral infligido).

Para tratar destas questões que nos impusemos e de outras tantas, dividimos o presente trabalho em três Partes. A PARTE I, intitulada "Direitos da Personalidade Relacionados à Integridade Moral e Colisão de Princípios Constitucinais", foi dividida em 8 (oito) capítulos e nos permitiu abordar com alguma profundidade, nos 3 primeiros capítulos, os conceitos de personalidade e de direitos da personalidade, as características destes últimos e seu paralelismo com os direitos fundamentais e as liberdades públicas.

No Capítulo 4 da PARTE I tratamos da "Liberdade de Expressão e de Manifestação do Pensamento", trazendo notícia da evolução histórica desta importante garantia conquistada pela civilização, abordando questões como as normas matrizes internacionais (Declarações e Tratados), os casos de abuso desse importante direito e as limitações reconhecidas a esta garantia a um só tempo política e de pleno desenvolvimento da personalidade. Neste capítulo se abordou a questão da vedação do hate speech muito em voga nestes tempos conflagrados, em que o semi-anonimato das redes sociais aumenta exponencialmente a "valentia" e a manifestação odienta.

\footnotetext{
${ }^{2}$ MINOZZI, Alfredo. Studio sul danno non patrimoniale (danno morale). 3za ed., Milano: Soc. Editrice, 1917, tradução livre de: "la distinzione del danno in patrimoniale ed non patrimoniale non si riferisce al danno nella sua origine, ma al danno nei suoi effetti. Quando parleremo di danni non patrimoniali, intendiamo parlare di danni che non ledono il patrimonio della persona. Il contenuto di questi danni non è il danaro, nè una cosa commercialmente reducibile in danaro, ma il dolore, lo spavento, l'emozione, l'onta, lo strazio fisico o morale, in generale una dolorosa sensazione provata dalla persona, attribuendo alla parola dolore il più largo significato".
} 
No capítulo subsequente (capítulo 5 da PARTE I) tratamos de conceituar, posicionar no tempo, no espaço e na sistemática jurídica os institutos da honra, imagem, intimidade e privacidade, trazendo sempre a contribuição das doutrina e jurisprudência estrangeiras e pontuando com alguns casos rumorosos no Brasil a envolver a proteção desses aspectos da personalidade. Os três capítulos finais desta PARTE I (caps. 6, 7 e 8) dedicam-se à colisão dos princípios em choque na hipótese principal de nosso estudo, ou seja, na colisão entre a liberdade de expressão de um lado e a proteção a direitos da personalidade alheios de outro; tratando, da forma mais aprofundade que conseguimos fazer, da necessidade da ponderação (sem considerações apriorísticas) sempre em vista do caso concreto, de forma a indicar qual a preponderância, in casu, dos princípios colidentes e saber se houve dano moral a mitigar ou não.

A PARTE II do trabalho, intitulada "Dano moral: Evolução Histórica do instituto, Conceito e Fenômeno do dano moral em face das Pessoas Jurídicas”, divide-se em 6 (seis) capítulos, sendo os 3 (três) primeiros dedicados a uma revisão de toda a polêmica doutrinária de que foi (e é) vítima a aplicação do instituto, desde o século XIX, a partir da ideia da imoralidade do pretium doloris e da absoluta impossibilidade jurídica de compensar coisas de natureza compleamente distinta, "senza l'unità di misura", no dizer de um inconformado GABBA, veemente opositor da reparabilidade dos danos morais. Posto que talvez um pouco longa, esta porção de nosso estudo, quer nos parecer fundamental como explicação das dificuldades enfrentadas até hoje para a aplicação desabrida, e sem peias da mitigação in pecunia dos danos morais. Procuramos recorrer às fontes clássicas (italianas, francesas, alemãs, portuguesas etc) que alimentaram os debates e que, entre nós, foram visitadas, em primeiro lugar, por Wilson Melo da Silva, Ávio Brasil, Alsino de Paula Salazar e depois por Youssef Said Cahali, Walter Moraes e Arthur Oliveira Deda. Discussões que, modernamente, vêm sendo travadas com proficiência e erudição por Claudio Luiz Bueno de Godoy, Carlos Edson do Rêgo Monteiro Filho, Maria Celina Bodin de Moraes et alteram.

Nos capítulos 4 e 5 que se seguem, nos aproximamos de Antonio Junqueira de Azevedo - e da ideia de dano-evento e dano-prejuízo -, bem como de Alfredo Orgaz, e formulamos um nosso entendimento do que deva presidir o conceito mais tecnicamente preciso de Dano Moral. No último capítulo desta PARTE II (cap. 6) tratamos do fenômeno do dano moral em face das pessoas jurídicas, expondo os autores favoráveis e contrários a que se admita às pessoas ideais sofrer danos morais, em que pese a Súmula $n^{\circ} 227$ da Jurisprudência do Egrégio Superior Tribunal de Justiça. 
Finalmente, depois de passar pela descrição do DIREITO (PARTE I) a ser protegido e da LESÃO (PARTE II) que este direito pode sofrer, partimos para a última divisão deste trabalho, (a PARTE III) que cuida da TUTELA em face dessa potencial lesão. A PARTE III, intitulada “Tutela Preventiva e Mitigação dos Danos Morais por ofensa à Honra, à Imagem, à Intimidade e à Privacidade", também se divide em 8 (oito) capítulos, sendo o primeiro deles todo dedicado à tutela civil inibitória ou preventiva. Aqui fazemos um histórico do surgimento entre nós e alhures da repulsa do direito à censura e procuramos analisar as semelhanças e diferenças entre a censura prévia, vedada pela $\mathrm{CF} / 1988$ e a possibilidade de o Judiciário impedir lesão ou iminente ameaça de lesão a direito, garantida pelo inciso XXXV do art. $5^{\circ}$ da CF/1988. Pontuamos, neste ponto, a discussão com casos concretos de interesse geral para melhor exemplificar as questões postas em disputa.

Nos três capítulos que se seguem (caps. 2, 3 e 4 da PARTE III), tratamos da tutela dita "reparatória", a que propomos redesignar como mitigatória, começando com um breve, porém necessário, retrospecto do que foi a evolução da RESPONSABILIDADE CIVIL ao longo da história da civilização. Em seguida, exploramos o funcionamento do mecanismo de mitigação dos danos morais de forma a poder abrir caminho para tratar, nos quatro capítulos finais dos problemas práticos a envolver esta operação.

O primeiro dos desafios práticos que enfrentamos - no capítulo 5 da PARTE III - é o da inconstitucionalidade das leis que propunham a "tarifação" ou o "tabelamento" do quantum mitigatório dos danos morais. Estaria correta tal vedação ou a compreensão de que tal previsão não foi recepcionada pela nova ordem constitucional instaurada a partir de 1988 ? Há utilidades ou vantagens em estabelecer-se "preços fechados” para cada espécie de direito da personalidade vulnerado? Todos os indivíduos terão sofrido o exato mesmo dano em circunstâncias fáticas semelhantes? São questões a nos desafiar neste ponto do trabalho.

Em seguida (cap. 6), passamos a discutir a aplicabilidade dos punitive damages do Direito Norte-Americano entre nós. Por ser instituto da tradição da Commom Law, poderia ser traladado para o nosso direito sem uma "tropicalização"? Prescindiria de alterações legislativas que permitissem sua aplicação, podendo dar-se por interpretação pretoriana apenas? Aqui trazemos inúmeros casos concretos e notícias recentes quanto à aplicação do instituto nos Estados Unidos da América do Norte, de forma a desfazer alguns mitos que se formaram em torno de tão controverso instrumento da Responsabilidade Civil. Também neste capítulo abordamos o DANO SOCIAL preconizado por Antonio Junqueira de Azevedo e 
que, assim como os punitive damages, teria função exemplificativa e se justificaria pela diminuição da qualidade de vida geral de toda a comunidade, abalada por práticas danosas reincidentes e de alta reprovabilidade por parte do agente lesante.

No penúltimo capítulo abordamos o método bifásico inaugurado pelas Colendas $3^{\mathrm{a}}$ e $4^{\mathrm{a}}$ Turmas Julgadoras do Egrégio Superior Tribunal de Justiça, que consiste em dividir a fixação do quantum mitigatório do dano moral em duas fases: a primeira delas aplicando um valor inicial colhido de um grupo de precedentes, "grupo de casos típicos”, com suportes fáticos idênticos e, numa segunda fase, chegar ao valor final da condenação, a partir da análise das circunstâncias do fato a partir de critérios objetivos dispostos por aquele sodalício, como: o grau de culpabilidade do agente; a gravidade do ato ilícito em si e sua repercussão na vítima; as condições sócio-econômicas das partes envolvidas etc.

O último capítulo dedicâmo-lo ao "problema da fixação do quantum mitigatório: arbitramento judicial e tentativa de balizamento legal", tentando mostrar um panorama o mais amplo possível daquilo que os mais diversos autores indicam como elementos a ser levados em consideração pelo magistrado no momento da fixação (arbitramento por equidade) do quantum mitigatório dos danos morais. É neste ponto que oferecemos nossas sugestões de lege ferenda para que adequações nas singeleza e retidão ortodoxa do art. 944 CC/2002 ("a indenização mede-se pela extensão do dano") possam tornar possível uma mensuração da mitigação baseada em critérios outros - que substituam a pura subjetividade judicial e que permitam a valorização de circunstâncias agravantes e atenuantes desse quantum mitigatório. 


\section{CONCLUSÃO}

Não obstante já produzidas as conclusões parciais, a primeira delas (PARTE I) voltada ao direito, a segunda (PARTE II) ao dano e a terceira (PARTE III) à tutela em face da perpetração do dano - sendo que o cerne dos textos ali produzidos deixaremos de aqui reproduzir de forma a evitar tautologia e cansar mais do que o necessário a prestigiosa banca, em virtude da extensão do presente trabalho que, infelizmente, se fez necessária por conta da complexidade dos temas envolvidos - entendemos conveniente elencar pontualmente as mais emblemáticas conclusões a que chegamos ao final deste estudo:

1. Em que pese o paralelismo no conteúdo dos direitos da personalidade, dos direitos fundamentais e das liberdades públicas; é o Direito Civil o locus do nascedouro e da disciplina dos direitos da personalidade e o foro onde encontrar-se o deslinde dos conflitos a envolvê-los - mesmo que a constitucionalização de algum desses direitos obrigue o civilista a manejar as técnicas de Direito Constitucional para aplicação de seus princípios.

2. A distinção entre dano moral e dano material (extrapatrimonial ou patrimonial) se dá em virtude da natureza do bem onde repercute a lesão (dano-prejuízo) e não em virtude daquela do bem que sofre o ataque (dano-evento).

3. Dano moral é a lesão - dano-prejuízo - que injustamente repercute no patrimônio ideal de pessoa física ou jurídica, onde compreendidos os seus direitos da personalidade, e que, em geral, provoca menoscabo anímico pelo abalo de suas afeições legítimas ou de seu equilíbrio psicológico, inocorrente no caso das pessoas jurídicas e presumido com relação às pessoas naturais privadas de discernimento; não possuindo tal lesão caráter patrimonial, mas podendo ter sido originada de um ataque - dano-evento - a bem da vida de natureza patrimonial ou extrapatrimonial.

4. O conceito de imagem-atributo se sobrepõe ao conceito de honra subjetiva e a noção de imagem deve limitar-se à identificação biotípica da pessoa, deixando reputação e 
atributos de natureza social para o conceito de honra. A lei não traz palavras inúteis e o artigo $5^{\circ}, \mathrm{X} \mathrm{da} \mathrm{CF/1988} \mathrm{traz} \mathrm{os} \mathrm{dois} \mathrm{vocábulos} \mathrm{como} \mathrm{bens} \mathrm{da} \mathrm{vida} \mathrm{distintos} \mathrm{a} \mathrm{merecer} \mathrm{proteção}$ autônoma.

5. Não existe uma maior valoração apriorística da liberdade de expressão, fundada numa suposta "supremacia do interesse púbico", em confronto com a inviolabilidade dos direitos da personalidade dos particulares. A ponderação far-se-á em condições estritas de paridade. 


\section{REFERÊNCIAS BIBLIOGRÁFICAS}

\section{LIVROS}

\section{Obras Gerais}

ALBERDI, Juan Bautista. Obras Completas. Buenos Aires: Ed. Tea, 1886, t. IV

ALMEIDA, Francisco de Paula Lacerda de. Obrigações. 2a ed. São Paulo: Revista dos Tribunaes, 1916

ASCENSÃO, José de Oliveira. O direito: introdução e teoria geral - uma perspectiva lusobrasileira. Lisboa: Fundação Calouste Gulbenkian, 1977

AZEVEDO, Antonio Junqueira de. Cadastros de restrição do crédito. Conceito de dano moral. in Estudos e pareceres de direito privado. São Paulo: Saraiva, 2004

. Novos estudos e pareceres de direito privado. São Paulo: Saraiva, 2009

BASTOS, Celso Ribeiro; MARTINS, Ives Gandra da Silva. Comentários à constituição do brasil. São Paulo: Saraiva, 1998

BAUDRY-LACANTINERIE, Gabriel; BARDE, Louis et alteram. Tratatto teorico pratico di diritto civile. Delle Obligazioni. Tomo IV. Milano: Dott. Francesco Villardi, 1925

BEVILÁQUA, Clóvis. Código civil. $11^{\mathrm{a}}$ ed., Rio de Janeiro: Francisco Alves, 1956, v. I

BORDA, Guillermo. Tratado de derecho civil-obligaciones. $7^{\mathrm{a}}$ ed., Buenos Aires: Perrot, 1994

BRUNO, Aníbal. Direito penal. Parte especial. São Paulo: Forense, 1966 
BURDESE, Alberto. Manuale di diritto privato italiano. Torino: UTET, 1974

CALMON, Pedro. História do Brasil. Rio de Janeio: José Olympio, 1959

CARBONNIER, Jean. Droit civil. Paris: PUF, 1969, v. 1

CARREJO, Simón. Derecho civil. Bogotá: Ed. Themis, 1972

CHAVES, Antônio. Tratado de direito civil. São Paulo: Revista dos Tribunais, 1985 . Lições de direito civil. Parte geral. São Paulo: Buschatsky/USP, 1972, vol. 3

CHINELlATO, Silmara Juny de Abreu; MACHADO, Antônio Cláudio da Costa (orgs.). Código Civil interpretado artigo por artigo, parágrafo por parágrafo. $7^{\mathrm{a}}$ ed., São Paulo: Manole, 2014

CORREIA, Alexandre; SCIASCIA, Gaetano. Manual de direito romano. $2^{\mathrm{a}}$ ed., São Paulo: Saraiva, 1953, vol. I e II

CRETELLA JÚNIOR, José. Curso elementar de direito romano. $22^{\mathrm{a}}$ ed., Rio de Janeiro: Forense, 1999

, Comentários à constituição brasileira de 1988. $2^{\mathrm{a}}$ ed., Rio de Janeiro: Forense Universitária, 1989

DANTAS, Francisco Clementino San Tiago. Programa de direito civil. Aulas proferidas na Faculdade Nacional de Direito. $4^{\mathrm{a}}$ ed., Rio de Janeiro: Editora Rio, 1979, vol. I, Parte Geral e vol. II, Obrigações e Contratos

DINIZ, Maria Helena. Curso de direito civil brasileiro. 23ª ed., São Paulo: Saraiva, 2009 
ENNECCERUS, Ludwig; KIPP, Theodor; WOLFF, Martin. Tratado de derecho civil. $3^{\mathrm{a}}$ edición española. Barcelona: Bosch Casa Editorial, 1966, Tradução: GONZALEZ, Blas Perez e ALGUER, José.

FERRARA, Francesco. Tratatto di diritto civile italiano. Roma: Atheneum, 1921, v. I

FERREIRA, Pinto. Comentários à constituição brasileira. São Paulo: Saraiva, 1989

FONSECA, Arnoldo Medeiros da. Repertório enciclopédico do direito brasileiro. $13^{\mathrm{a}}$ edição, CARVALHO SANTOS, J. M. de (org.). Rio de Janeiro: Freitas Bastos S.A., v. 14, 1984

GABBA, Carlo Francesco. Questioni di diritto civile. 2a ed. Torino: UTET, 1911

GHESTIN, Jacques. Traité de droit civil. $4^{\mathrm{a}}$ ed., Paris: LGDJ, 2017

GUSMÃO, Paulo Dourado de. Introdução à ciência do direito. Rio de Janeiro: Forense, 1956

HOUAISS, Antônio. Dicionário Houaiss da língua portuguesa. Rio de Janeiro: Objetiva, 2004

HUNGRIA, Nelson. Comentários ao código penal. $4^{\mathrm{a}}$ ed., Rio de Janeiro: Forense, 1958, v. VI

JOSSERAND, Louis. Derecho civil. Tomo I, vol. I. Buenos Aires: Bosch y Cía. Editores, 1950, trad. Santiago Cunchillos y Manterola

LACERDA, Paulo M. de. Manual do código civil brasileiro, v. II, Rio de Janeiro: Jacintho Ribeiro dos Santos Editor, 1930

LALOU, Henry, Traité Practique de la responsabilité civile. Paris, 1949 
LOMONACO, Giovanni. Istituizioni di diritto civile italiano. Milano: Giuffrè, 1894, v. III

MALUF, Carlos Alberto Dabus e MALUF, Adriana Caldas do Rego Freitas Dabus. Introdução ao direito civil. São Paulo: Saraiva, 2017

MARKY, Thomas. Curso elementar de direito romano. São Paulo: Saraiva, 1995, $8^{\mathrm{a}} \mathrm{ed}$.

MARTINS, Leonardo. Tribunal constitucional federal alemão. Decisões anotadas sobre direitos fundamentais. São Paulo: Konrad Adenauer Stiftung, 2018, vols. I e II

MENDES, Gilmar Ferreira; BRANCO, Paulo Gustavo Gonet. Curso de direito constitucional. $11^{\mathrm{a}}$ ed, São Paulo: Saraiva, 2016

MENEZES CORDEIRO. Teoria geral do direito civil. Lisboa: Associação Académica da Fac. de Direito de Lisboa, v. 1, 1994

MESSINEO, Francesco. Manuale di diritto civile e commerciale. $9^{\text {a }}$ edizione, Milano: Dott. A. Giuffrè Editore, 1965, v. secondo

MIRANDA, Jorge. Manual de direito constitucional: direitos fundamentais. Tomo IV. $2^{\mathrm{a}}$ ed., Coimbra: Coimbra Editora, 1993

MONTEIRO, Washington de Barros; MALUF, Carlos Alberto Dabus e SILVA, Regina Beatriz Tavares da. Curso de direito civil. Direito das obrigações. $39^{\mathrm{a}}$ ed, São Paulo: Saraiva, 2012, v. 5

MOREIRA ALVES, José Carlos. Direito romano. $18^{\mathrm{a}}$ ed., Rio de Janeiro: Forense, 2018

OLIVEIRA, James Eduardo. Código civil comentado e anotado. $2^{\mathrm{a}}$ ed. Rio de Janeiro: Forense, 2010

ORGAZ, Alfredo. Derecho civil argentino - Personas individuales. Buenos Aires: Editorial Depalma, 1946 
PEREIRA, Caio Mário da Silva. Instituições de direito civil. $18^{\mathrm{a}}$ ed., Rio de Janeiro: Forense, v. 1, 1999

PONTES DE MIRANDA, Francisco Cavalcanti. Tratado de direito privado. São Paulo: Revista dos Tribunais, 2012, Tomos I, II,VII e XXVI

RODRIGUES, Silvio. Direito civil. V. 4. Responsabilidade civil. 32a ed, São Paulo: Saraiva, 2002

SANTOS, J. M. Carvalho. Código civil brasileiro interpretado. Rio de Janeiro: Freitas Bastos, 1958

SERPA LOPES, Miguel Maria de. Curso de direito civil. $4^{\mathrm{a}}$ ed., Rio de Janeiro: Livraria Freitas Bastos, 1962

SILVA, José Afonso da. Curso de direito constitucional positivo. $5^{\mathrm{a}}$ ed., São Paulo: Revista dos Tribunais, 1989

TEIXEIRA DE FREITAS, Augusto. Consolidação das leis civis. $3^{\mathrm{a}}$ ed. Rio de Janeiro: B. L. Garnier, 1876

TELLES, Inocêncio Galvão. Direito das obrigações. $3^{\text {a }}$ ed., Coimbra: Coimbra Editora, 2007

TEPEDINO, Gustavo; BARBOZA, Heloisa Helena; MORAES, Maria Celina Bodin de. Código civil interpretado conforme a constituição da república. Rio de Janeiro: Renovar, 2004 Temas de direito civil. Rio de Janeiro: Renovar, 1999

TRABUCCHI, Alberto. Istituzioni di diritto civile. 13ª edizione, Padova: CEDAM, 1962

VENOSA, Sílvio de Salvo. Direito Civil-parte geral. 9a ed., São Paulo: Atlas, v. 1, 2009 
VON TUHR, Andrea. Tratado de las obligaciones. Madrid: Reus, 1934

WALD, Arnoldo. Curso de direito civil brasileiro. São Paulo: RT, 1989, v. 2

ZEA, Arturo Valencia. Derecho civil. Bogotá: Ed. Themis, 1973

\section{OBRAS MONOGRÁFICAS}

ALEXY, Robert. Teoria dos direitos fundamentais. $2^{\mathrm{a}}$ ed., Tradução de Virgílio Afonso da Silva. São Paulo: Malheiros, 2015

ALSINA, Jorge Bustamante. Teoria general de la responsabilidade civil. Buenos Aires: Abeledo-Perrot, 1993

ALVIM, Agostinho. Da inexecução das obrigações e suas consequências. $3^{\mathrm{a}}$ ed. Rio de Janeiro: Jurídica e Universitária, 1965

ANDRADE, Manuel da Costa. Liberdade de imprensa e inviolabilidade pessoal - Uma perspectiva jurídico-criminal. Coimbra: Coimbra Editora, 1996

ARAMENDIA, José Pedro. A reparação do dano moral na doutrina e no código civil uruguaio. RF 105:38

ARAÚJO, Luiz Alberto David de. A proteção constitucional da própria imagem. Belo Horizonte: Del Rey, 1996

ARENHART, Sérgio Luiz. A tutela inibitória da vida privada. São Paulo: Revista dos Tribunais, 2000 
ARRUDA, Augusto F. M. Ferraz de. Dano moral puro ou psíquico. São Paulo: Ed. Juarez de Oliveira, 1999

ASSIS NETO, S. J. Dano moral - aspectos jurídicos. São Paulo: Bestbook, 1998

ÁVILA, Humberto. Teoria dos princípios - da definição à aplicação dos princípios jurídicos. $16^{\mathrm{a}}$ ed, São Paulo: Malheiros, 2015

AZEVEDO, Álvaro Villaça. Teoria geral das obrigações e responsabilidade civil. 12a ed., São Paulo: Atlas, 2011,

BARCELLOS, Ana Paula de. A eficácia jurídica dos princípios constitucionais: o princípio da dignidade da pessoa humana. Rio de Janeiro: Renovar, 2002

BARENDT, Eric. Freedom of Speech. New York: Oxford University Press, 2nd ed., 2005

BARROSO, Luiz Roberto. A nova interpretação constitucional: ponderação, direitos fundamentais e relações privadas. $3^{\mathrm{a}} \mathrm{ed}$, Rio de janeiro: Renovar, 2008

BENUCCI, Edoardo. La responsabilità civile. Milano: Giuffrè, 1955

BITTAR, Carlos Alberto. Os direitos da personalidade. $6^{\mathrm{a}}$ ed, atualizada por Eduardo C. Bianca Bittar. São Paulo: Forense Universitária, 2006 Reparação civil por danos morais. 2a ed., São Paulo: Revista dos Tribunais, 1994

BITTAR, Eduardo C. Bianca. Metodologia da pesquisa jurídica. 13ª ed., São Paulo: Saraiva, 2015

BOBBIO, Norberto. A era dos direitos. 11 a ed., Rio de Janerio: Editora Campus, 1992. Trad. Carlos Nelson Coutinho 
BORNHOLDT, Rodrigo Meyer. Liberdade de expressão e direito à honra. Uma nova abordagem no direito brasileiro. Joinville: Bildung, 2010

BRASIL, Avio. O dano moral no direito brasileiro. Rio de Janeiro: Livraria Jacinto Editora, 1944

BREBBIA, Roberto H.. El daño moral. Buenos Aires: Bibliografia Argentina, 1950

CAHALI, Yussef Said. Dano moral. 2a ed, São Paulo: Revista dos Tribunais, 1998

CALDAS, Pedro Frederico. Vida privada, liberdade de imprensa e dano moral. São Paulo: Saraiva, 1997

CAMPOS, Diogo Leite de. Lições de direitos da personalidade. Coimbra: Almedina, 1995

CANOTILHO, José Joaquim Gomes; MACHADO, Jónatas E. M. e GAIO JUNIOR, Antônio Pereira. Biografia não autorizada versus liberdade de expressão. Curitiba: Juruá, 2015

CAPELO DE SOUZA, Rabindranath Valentino Aleixo. O direito geral de personalidade. Coimbra: Coimbra Editora, 1995

CARETTI, Paolo. Diritto dell'informazione e della comunicazione - Stampa, radiotelevisione, telecomunicazioni, teatro e cinema. $5^{\text {a }}$ edizione. Bologna: Il Mulino, 2013

CARNEIRO, Maria Francisca. Pesquisa jurídica - metodologia da aprendizagem, aspectos, questões e aproximações. $7^{\mathrm{a}}$ ed., Curitiba: Juruá, 2011

CARVAlHO, Márcia Haydée Porto de. A defesa da honra e o direito à informação. Florianópolis: Letras Contemporâneas, 2002

CARVALHO NETO, Inacio de. Abuso do direito. Biblioteca de estudos em homenagem ao professor Arruda Alvim. 6 ${ }^{\text {a }}$ d. revista e atualizada, Curitiba: Juruá, 2015 
CAVALIERI FILHO, Sergio. Programa de responsabilidade civil. $7^{\mathrm{a}} \mathrm{ed}$.,

São Paulo: Atlas, 2007

CENDON, Paolo. I danni non patrimonial oggi. Milano: Key Editore, 2015

CHAVES, Antônio. Responsabilidade pré-contratual. Rio de Janeiro: Forense, 1959

CHEQUER, Cláudio. A liberdade de expressão como direito fundamental preferencial prima facie. $2^{\mathrm{a}}$ ed., Rio de Janeiro: Lumen Juris, 2017

CHIRONI, Gian Pietro. La colpa nel diritto civile odierno - Colpa extra-contrattuale, $2^{\mathrm{a}}$ ed., 2 vol. Torino: UTET, 1903

CIFUENTES, Santos. Derechos personalísimos. Buenos Aires-Córdoba: Ed. Lerner, 1974 . El daño moral y la persona jurídica. in Derecho de daños. Primera parte. Buenos Aires: La Rocca, 1996

COSTA JÚNIOR, Paulo José da. O direito de estar só: tutela penal da intimidade. $4^{\mathrm{a}}$ ed., São Paulo: Revista dos Tribunais, 2007

CRETELLA JÚNIOR, José. Curso de liberdades públicas. Rio de Janeiro: Forense, 1986

DE CUPIS, Adriano. Il danno. Milanno: Giuffrè, 1946 I diritti della personalità. Milano: Dott. A. Giuffrè Editore, 1959

DIAS, José de Aguiar. Da responsabilidade civil. Rio de Janeiro: Forense, 1987

DI LAURO, Antonino Procida Mirabelli. La riparazione dei danni ala persona. Napoli: Edizioni Scientifiche Italiane, 1993 
DOTTI, René Ariel. Proteção da vida privada e liberdade de informação: possibilidades e limites. São Paulo: RT, 1980

DUVAL, Hermano. Direito à imagem. São Paulo: Saraiva, 1988

DWORKIN, Ronald. Levando os direitos a sério. Tradução de Nelson Boeira. São Paulo: Martins Fontes, 2002

ESTEVES, Paulo (org.). Dano moral - observações sobre a ação de responsabilidade civil por danos morais decorrentes do abuso da liberdade de imprensa. São Paulo: Fisco e Contribuinte, 1999

FACHIN, Luiz Edson. Direito civil - sentidos, transformações e fim. Rio de Janeiro: Renovar, 2015

FISCHER, Hans A.. Los daños civiles y su reparación. Madrid: Libreria General de Victoriano Suarez, 1928, Tradução espanhola por W. Roces

FISS, Owen M. A ironia da liberdade de expressão: estado, regulação e diversidade na esfera pública. Tradução de Gustavo Birembojm e Caio Mario da Silva Pereira Neto. Rio de Janeiro: Renovar, 2005

FLORIAN, Eugenio. L'ingiuria e la diffamazione. Torino: UTET, 1939

FRUET, Gustavo Bonato. Direito à informação: limites entre informação, comunicação e democracia. São Paulo: Atlas. 2012

GADELHO JUNIOR, Marcos Duque. Liberdade de imprensa e a mediação estatal. São Paulo: Atlas, 2015

GODOY, Claudio Luiz Bueno de. A liberdade de imprensa e os direitos da personalidade. $3^{\mathrm{a}}$ ed., São Paulo: Atlas, 2015

GOGLIANO, Daisy. Direitos privados da personalidade. São Paulo: Quartier Latin, 2013 
GONZÁLEZ, Matilde Zavala. Resarcimiento de daños. Buenos Aires: Hammurabi, 1993, vol. 2c

GROGNET, Diego Ortiz. La injuria y el daño moral. Buenos Aires: Imprenta Mercatali, 1932

GUERRA, Sidney Cesar Silva. A liberdade de imprensa e o direito à imagem. Rio de Janeiro: Renovar, 1999

JABUR, Gilberto Haddad. Liberdade de pensamento e direito à vida privada - conflito entre direitos da personalidade. São Paulo: Revista dos Tribunais, 2000

JONAS, Hans. O princípio da responsabilidade: ensaio de uma ética para a civilização tecnológica. Tradução de Marijane Lisboa e Luiz Barros Moritz. Rio de Janeiro: Contraponto; Ed. PUC-Rio, 2011

LEVENEUR, Laurent. Réforme du droit des contrats, du régime general et de la preuve des obligations. Paris: LexisNexis, 2018

LIRA, Rafael de Souza. Mídia sensacionalista - o segredo de justiça como regra. Rio de Janeiro: Forense, 2014

LOPEZ, Teresa Ancona. O dano estético: responsabilidade civil. $3^{\mathrm{a}}$ ed, São Paulo: Revista dos Tribunais, 2002

MAGAlHÃES, Teresa Ancona Lopez de. O dano estético (responsabilidade civil). São Paulo: Revista dos Tribunais, 1980

MARCHI, Eduardo C. Silveira. Guia de metodologia jurídica. 2a ed., São Paulo: Saraiva, 2009

MATIELO, Fabrício Zamprogna. Dano moral, dano material e reparação. $3^{\mathrm{a}}$ ed, Porto Alegre: Sagra Luzzatto, 1997 
MATOS, Eneas de Oliveira. Dano moral e dano estético. Rio de Janeiro: Renovar, 2008 . Erro médico e o judiciário: teoria e prática da responsabilidade civil médica e sua interpretação jurisprudencial. São Paulo: Academia Olímpia, 2015

MELO, Nehemias Domingos de. Dano moral - Problemática do cabimento à fixação do quantum. 2a ed., São Paulo: Atlas, 2011

MIGLIORE, Alfredo Domingues Barbosa. Direito além da vida. Um ensaio sobre os direitos da personalidade post mortem. São Paulo: LTr, 2009

, Personalidade jurídica dos grandes primatas. Belo Horizonte: Del Rey, 2012

MINOZZI, Alfredo. Studio sul danno non patrimoniale (danno morale). 3za ed., Milano: Soc. Editrice, 1917

MIRANDA, Jorge; RODRIGUES JUNIOR, Otávio Luiz; FRUET, Gustavo Bonato (orgs.). Direitos da personalidade. São Paulo: Atlas, 2012

MONTEIRO FILHO, Carlos Edson do Rêgo. Elementos de responsabilidade civil por dano moral. Rio de Janeiro: Renovar, 2000

MONTEL, Alberto. Problemi della responsabilità e del danno. Torino: G. Giappichelli Editore, 1952

MORAES, Maria Celina Bodin de. Danos à pessoa humana. Uma leitura civil-constitucional dos danos morais. $2^{\mathrm{a}}$ ed. revista, Rio de Janeiro: Ed. Processo, 2017

MORATO, Antonio Carlos. Direito de autor em obra coletiva. São Paulo: Saraiva, 2007 . A pessoa jurídica consumidora. São Paulo: Revista dos Tribunais, 2008 
NUNES, Luiz Antonio Rizzatto; CALDEIRA, Mirella D’Angelo. O dano moral e sua interpretação jurisprudencial. São Paulo: saraiva, 1999

. Manual da monografia jurídica. $7^{\text {a }}$ ed., São Paulo: Saraiva, 2009

NUNES JUNIOR, Vidal Serrano. A proteção constitucional da informação e o direito à crítica jornalística. São Paulo: FTD, 1997

OLIVEIRA NETO, Olavo de. Manual da monografia jurídica. 2a ed., São Paulo: Verbatim, 2013

ORGAZ, Alfredo. El daño resarcible (actos ilícitos). Buenos Aires: Editorial Bibliografica Argentina, 1952

OST, François. O tempo do direito. Trad. Élcio Fernandes, Bauru: EDUSC, 2005

PEREIRA, Caio Mário da Silva. Responsabilidade Civil. $3^{\mathrm{a}}$ ed. revista e atualizada, Rio de Janeiro: Forense, 1992

PEREIRA, Guilherme Döring Cunha. Liberdade e responsabilidade dos meios de comunicação. São Paulo: Revista dos Tribunais, 2002

PIMENTA BUENO, José Antônio. Direito publico brazileiro e analyse da constituição do imperio. Rio de Janeiro: Typ. Imp. e Const. de J. Villeneuve e C., 1857

PIZARRO, Ramon Daniel. Responsabilidad civil de los medios masivos de comunicación. Daños por noticias inexactas o agraviantes. Buenos Aires: Editorial Hammurabi, 1991

POTIGUAR, Alex. Liberdade de expressão e o discurso de ódio - A luta pelo reconhecimento da igualdade como direito à diferença. Brasília: Ed. Consulex, 2012

REIS, Clayton. Avaliação do dano moral. Rio de Janeiro: Forense, 1998 
RIGAMONTE, Paulo Arthur Germano; SILVEIRA, Daniel Barile da. Liberdade de expressão e humor. Curitiba: Juruá, 2018

RIPERT, Georges. A regra moral nas obrigações civis. São Paulo: Saraiva, 1937. Tradução da $3^{\mathrm{a}}$ ed. francesa por Osório de Oliveira

RODOTÀ, Stefano. A vida na sociedade da vigilância. A privacidade hoje. Rio de Janeiro: Renovar, 2008, Trad.: Danilo Doneda e Luciana Cabral Doneda

, Il mondo nella rete - Quali i diritti, quali i vincoli. Roma: Editori Laterza, 2014

RODRIGUES JUNIOR, Álvaro. Liberdade de expressão e liberdade de informação. Limites e formas de controle. Curitiba: Juruá Editora, 2009

SAINT-PAU, Jean-Christophe (org.) et. alt. Droits de la personnalité. Paris: LexisNexis, 2013

SALAZAR, Alcino de Paula. Reparação do dano moral. Rio de Janeiro: Borsoi, 1943

SANTINI, José Raffaelli. Dano moral - doutrina, jurisprudência e prática. São Paulo: Led, 1997

SANTOS, Antonio Jeová. Dano moral indenizável. $6^{\text {a }}$ ed., Salvador: JusPodivm, 2016

SARLET, Ingo Wolfgang. Dignidade da pessoa humana e direitos fundamentais na constituição federal de 1988. Porto Alegre: Livraria do Advogado, 2001

SARMENTO, Daniel. A ponderação de interesses na constituição federal. Rio de Janeiro: Lumen Iures, 2003

SCALISI, Antonino. Il diritto alla riservatezza. Il diritto all'immagine, il diritto al segreto, la tutela dei dati personali, il diritto alle vicende della vita privata, gli strumenti di tutela. Milano: Giuffrè Editore, 2002 
SCHREIBER, Anderson. Direitos da personalidade. $3^{\text {a }}$ ed., São Paulo: Atlas, 2014, . Novos paradigmas da responsabilidade civil - da erosão dos filtros da reparação à diluição dos danos. $6^{\text {a }}$ ed., São Paulo: Atlas, 2015 . KONDER, Carlos Nelson (orgs.). Direito civil constitucional. São Paulo: Atlas, 2016

SELLA, Mauro. La responsabilità civile - I danni morali. Torino: UTET GIURIDICA, 2013, in Il diritto italiano nella giurisprudenza, CENDON, Paolo (org.)

SERRANO JUNIOR, Odoné. Introdução à contemporânea teoria dos direitos fundamentais. Curitiba: Juruá, 2010

SILVA, Américo Luís Martins da. O dano moral e a sua reparação civil. São Paulo: Revista dos Tribunais, 1999

SILVA, Edson Ferreira da. Direito à intimidade. São Paulo: Oliveira Mendes, 1998

SILVA, Wilson Melo da. O dano moral e sua reparação. Rio de Janeiro: Revista Forense, 1955 O dano moral e sua reparação. $2^{\mathrm{a}}$ ed., Rio de Janeiro: Revista Forense, 1969,

SOUSA, Rabindranath V. A. Capelo de. O direito geral de personalidade. Coimbra: Coimbra Editora, 1995

STOCO, Rui. Responsabilidade civil e sua interpretação jurisprudencial. $3^{\mathrm{a}}$ ed., São Paulo: Revista dos Tribunais, 1997

SZANIAWSKI, Elimar. Direitos de personalidade e sua tutela. São Paulo: RT, 1993

THEODORO JÚNIOR, Humberto. Dano moral. $6^{\text {a }}$ ed., São Paulo: Ed. Juarez de Oliveira, 2009 
VALLER, Wladimir. A reparação do dano moral no direito brasileiro. São Paulo: EV Editora, 1997

VARGAS, Glaci de Oliveira Pinto. Reparação do dano moral-controvérsias e perspectivas. $3^{\mathrm{a}}$ ed, Porto Alegre: Síntese, 1998

VENTURINI, Beatriz. El daño moral en nuestra jurisprudencia y en el derecho comparado. $2^{a}$ edicion corregida, actualizada y ampliada, Montevideo: FCU, 1992

VINEY, Geneviève; JOURDAIN, Patrice; CARVAL, Suzanne. Les conditions de la responsabilité. $4^{\mathrm{a}}$ ed., Paris: LGDJ, 2013

. Les effets de la responsabilité. $4^{\mathrm{a}}$ ed., Paris: LGDJ, 2017

ZENUN, Augusto. Dano moral e sua reparação. 6a ed, Rio de Janeiro: Forense, 1997

\section{CAPÍTULOS DE LIVROS}

CHINELlATO, Silmara Juny de Abreu. Direitos da personalidade: o art. 20 do c.c. e a biografia das pessoas notórias, in CASSETARI, Cristiano (org.). 10 anos de vigência do código civil brasileiro de 2002. Estudos em homenagem ao prof. Carlos Alberto Dabos Maluf. São Paulo: Saraiva, 2013

. Da responsabilidade civil no código de 2002: aspectos fundamentais. Tendências do direito contemporâneo, in TEPEDINO, Gustavo; FACHIN, Luiz Edson (coords.). O direito e o tempo: embates jurídicos e utopias contemporâneas. Estudos em homenagem ao prof. Ricardo Pereira Lira. Rio de Janeiro: Renovar, 2008

DEDA, Artur Oscar Oliveira. Dano moral (reparação). in Enciclopédia Saraiva do direito. FRANÇA, Rubens Limongi (coord.), São Paulo: Saraiva, 1977, v. 22 
FONSECA, Arnoldo Medeiros da. Repertório enciclopédico do direito brasileiro. v. 14, $11^{\mathrm{a}}$ ed., CARVALHO SANTOS, J.M. (coord.), Rio de Janeiro: Freitas Bastos, 1986

FRANÇA, Rubens Limongi. Direitos da personalidade I, in Enciclopédia Saraiva do direito. FRANÇA, Rubens Limongi (coord.), São Paulo: Saraiva, 1977, vol. 28

FUJITA, Jorge Shiguemitsu. Responsabilidade civil: indenização por equidade no novo código civil. in Ensaios sobre responsabilidade civil na pós-modernidade. HIRONAKA, Giselda Maria Fernandes Novaes; FALAVIGNA, Maria Clara Osuna Diaz (orgs.). Porto Alegre: Magister, 2007

GODOY, Claudio Luiz Bueno de. CASSETARI, Christiano (coord.). Alguns apontamentos sobre o dano moral, sua configuração e o arbitramento da indenização. in 10 anos de vigência do código civil de 2002 - estudos em homenagem ao prof. Carlos Alberto Dabus Maluf. São Paulo: Saraiva, 2013

LOPEZ, Teresa Ancona. Principais linhas da responsabilidade civil no direito brasileiro contemporâneo, in AZEVEDO, Antonio Junqueira et. alt. (orgs.). Princípios do novo código civil brasileiro e outros temas. Homenagem a Tulio Ascarelli. São Paulo: Quartier Latin, 2008

MATOS, Eneas de Oliverira. Direito à integridade física e direito à saúde nas relações entre particulares, in MENEZES, Joyceane Bezerra de (org.). Dimensões jurídicas da personalidade na ordem constitucional brasileira. Florianópolis: Conceito Editorial, v. 1, p. 189-211, 2008

. Considerações sobre os danos morais reflexos no caso de ofensa à integridade física de terceiro e sua reparação na jurisprudência brasileira, in CAMILLO, Carlos Eduardo Nicoletti; SMANIO, Gianpaolo Poggio (org.). 60 desafios do direito - direito na sociedade contemporânea. São Paulo: Atlas, v. 1, 2013 
MATTIA, Fábio Maria de. Direitos da personalidade - II, in Enciclopédia Saraiva do direito, FRANÇA, Rubens Limongi (coord.), v. 28, São Paulo: Saraiva, 1977

MAZUR, Maurizio. A dicotomia entre os direitos de personalidade e os direitos fundamentais, in MIRANDA, Jorge; RODRIGUES JUNIOR, Otávio Luiz; FRUET, Gustavo Bonato (orgs.). Direitos da Personalidade. São Paulo: Atlas, p. 25-64, 2002

MIRANDA, Jorge; RODRIGUES JUNIOR, Otávio Luiz e FRUET, Gustavo Bonato. Principais problemas dos direitos da personalidade e estado-da-arte da matéria no direito comparado, in Direitos da personalidade. MIRANDA, Jorge; RODRIGUES JUNIOR, Otávio Luiz e FRUET, Gustavo Bonato (orgs.). São Paulo: Ed. Atlas. 2012.

MORAES, Walter. Direito da Personalidade, in Enciclopédia saraiva do direito, FRANÇA, Rubens Limongi (coord.), São Paulo: Saraiva, 1977, v. 26

MORATO, Antonio Carlos; DE CICCO, Maria Cristina. Direito ao esquecimento: luzes e sombras. In Estudos em homenagem a Ivette Senise Ferreira. SILVEIRA, Renato de Mello Jorge; GOMES, Mariângela Gama de Magalhães (orgs.), São Paulo: LiberArs, 2015, pp. $77-$ 102

PONTES DE MIRANDA, Francisco Cavalcanti. Manual do código civil brasileiro. Do direito das obrigações. LACERDA, Paulo de (coord.). Rio de Janeiro: Jacintho Ribeiro dos Santos Editor, 1929

RODRIGUES JUNIOR, Otavio Luiz. Do príncipe Bismarck à princesa Caroline de Mônaco: vida privada de pessoas célebres e as liberdades comunicativas no direito civil, in CASSETARI, Christiano (org.). 10 anos de vigência do c.c. de 2002. Estudos em homenagem ao prof. Carlos Alberto Dabos Maluf. São Paulo: Saraiva, 2013

SIDOU, J. M. Othon. Personalidade II, in Enciclopédia Saraiva do direito. FRANÇA, Rubens Limongi (coord.) São Paulo: Saraiva, 1977, v. 58 
SILVA, Wilson Melo da. Dano moral, in Enciclopédia Saraiva do direito, São Paulo: Saraiva, 1977, FRANÇA, Rubens Limongi (coord.), v. 22

VERCELLONE, Paolo. Diritti della personalità, in Novissimo digesto italiano. $3^{\mathrm{a}}$ edizione, Torino: UTET, 1957, v. XII

\section{ARTIGOS}

ARAMENDIA, José Pedro. A reparação do dano moral na doutrina e no código civil uruguaio, Revista Forense 105:38, out-dez 1946

AZEVEDO, Antonio Junqueira de. Caracterização jurídica da dignidade da pessoa humana, in RTDC, ano 2, vol 9, jan/mar 2002

BARRETO, Wanderley de Paula. Os direitos da personalidade na jurisprudência alemã contemporânea, in Revista Trimestral de Direito Civil, v. 41, p. 135-159, 2010

BARROSO, Luiz Roberto. Colisão entre liberdade de expressão e direitos da personalidade. Critérios de ponderação. Interpretação constitucionalmente adequada ao código civil e da lei de imprensa, in Revista Trimestral de Direito Civil, v. 10. Rio de Janeiro: Padma, 2003

BOYLE, Kevin. Hate speech. The United States versus the rest of the world? Maine, Maine Law Review, v. 53:2, 2001

CHINELLATO, Silmara Juny de Abreu. Biografias não autorizadas: liberdade de expressão, outros direitos de personalidade e direito do autor, in Cadernos de Pós-graduação em Direito: estudos e documentos de trabalho, v. 30, 2014

. Liberdade de expressão: direitos da personalidade e as biografias não autorizadas, in Revista Brasileira de Direito Comparado, v. 44/45, 2014 
DE MATTIA, Fábio Maria. Direitos da personalidade: aspectos gerais, in Revista Forense, São Paulo, v. 262, n. 898/900, abr/jun. 1978

DIREITO, Carlos Alberto Menezes. Os direitos da personalidade e a liberdade de expressão, in Revista Forense. Rio de Janeiro. v. 98, n. 363, p. 29-37, set/out 2002

FERRAZ JUNIOR, Tércio Sampaio. Sigilo de dados: o direito à privacidade e os limites à função fiscalizadora do Estado. Cadernos de Direito Constitucional e Ciência Política. São Paulo, v. 1. no 1, out/dez 1992

FRANÇA, Rubens Limongi. O direito civil como direito constitucional. São Paulo:RT. Revista de Direito Civil, RDCiv 54/189, out-dez/1990 . Direitos da personalidade: coordenadas fundamentais, in Revista dos Tribunais, São Paulo, v. 72, n. 567, p. 9-16, jan/1983

GRASSI, Aldo. Il concetto di danno punitivo, in Tagete, VI, fasc. 1, março de 2000

LIMA, Zulmira Pires de. Responsabilidade civil por danos morais. RF 83:219

LÔBO, Paulo Luiz Netto. Danos morais e direitos da personalidade, in RTDC, v. 6, abrjun/2001

MENDES, Gilmar Ferreira. Colisão de direitos fundamentais. Liberdade de expressão e de comunicação e direito à honra e à imagem, in Revista de Informação Legislativa. Brasília, v. 31, n. 122, p. 297-302, abr/jun, 1994

MORAES, Walter. Direito à própria imagem. São Paulo: RT 443/64, set/1972

MORATO, Antonio Carlos. Quadro geral dos direitos da personalidade. in Revista da Faculdade de Direito da Universidade de São Paulo, v. 106/107, jan/dez 2011/2012 
SZANIAWSKI, Elimar. Considerações sobre o direito à intimidade das pessoas jurídicas. São Paulo: RT 657/25, jul/1990

\section{TESES E DISSERTAÇÕES}

FERNANDES, André de Godoy. Meios de comunicação social no Brasil: promoção do pluralismo, direito concorrencial e regulação. Tese de Doutorado sob orientação do Professor Doutor Calixto Salomão Filho, defendida perante a Faculdade de Direito da Universidade de São Paulo. São Paulo, 2009

FLUMIGNAN, Silvano José Gomes. Dano-evento e dano-prejuízo. Dissertação de Mestrado sob orientação do Professor Titular Doutor Antônio Junqueira de Azevedo, defendida perante a Faculdade de Direito da Universidade de São Paulo. São Paulo, 2009

JABUR, Gilberto Haddad. Efeitos jurídicos da ameaça ou lesão a direitos personalíssimos por fato de comunicação social. Tese de Doutorado sob orientação da Professora Doutora Maria Helena Diniz, defendida perante a Pontifícia Universidade Católica de São Paulo. São Paulo, 2005

LÉCUYER, Guillaume. Liberté d'expression et responsabilité - Étude de droit privé. Thèse pour le doctorat en droit de l'Université Panthéon-Sorbonne (Paris I), Paris: présentée et soutenue publiquement le 4 octobre 2004. 


\section{TEXTOS EM MEIO ELETRÔNICO}

GALLO, Paolo. Punitive damages in Italy? Disponível em http://www.jus.unitn.it/cardozo. Acessado em 26/09/2017

GAUDENZI, Andrea Sirotti. Brevi note in tema di "danni punitivi". 2008. Disponível em http://www.studiosirottigaudenzi.it acessado em 25/09/2017

MONTEIRO FILHO, Carlos Edson do Rêgo. O conceito de dano moral nas relações de trabalho. Civilistica.com. Rio de Janeiro: a.3, n.1, jan-jun/2014. Disponível em http://civilistica.com/o-conceito-de-dano-moral-nas-relacoes-de-trabalho/ acessado em 10.08.2017

MUSY, A. M., Il mobbing ed il danno esistenziale: profili comparatistici, Atti del Convegno $\begin{array}{lllll}\text { A.G.A.N. } & - & 6 & \text { dicembre, } & 2000\end{array}$ http://www.agatavvocati.it/doc/Conferenza_mobbing_Novara.doc; acessado em 26/09/2017

STRECK, Lênio Luiz. Os presos da "lava jato", os índios, o voyeurismo e a atriz global subtese: "voyerar" presos é o mesmo que fazer selfie em velório. Disponível em http://www.conjur.com.br/2017-mar-16/senso-incomum-presos-lava-jato-indiosvoyeurismo-atriz-global acessado em 20 de agosto de 2018 